\title{
Post-earthquake fire resistance of steel buildings
}

\author{
Jelinek, T. ; Zania, V.; Giuliani, Luisa
}

Published in:

Journal of Constructional Steel Research

Link to article, DOI:

10.1016/j.jcsr.2017.08.021

Publication date:

2017

Document Version

Peer reviewed version

Link back to DTU Orbit

Citation (APA):

Jelinek, T., Zania, V., \& Giuliani, L. (2017). Post-earthquake fire resistance of steel buildings. Journal of Constructional Steel Research, 138, 774-782. https://doi.org/10.1016/j.jcsr.2017.08.021

\section{General rights}

Copyright and moral rights for the publications made accessible in the public portal are retained by the authors and/or other copyright owners and it is a condition of accessing publications that users recognise and abide by the legal requirements associated with these rights.

- Users may download and print one copy of any publication from the public portal for the purpose of private study or research.

- You may not further distribute the material or use it for any profit-making activity or commercial gain

- You may freely distribute the URL identifying the publication in the public portal

If you believe that this document breaches copyright please contact us providing details, and we will remove access to the work immediately and investigate your claim 


\title{
POST-EARTHQUAKE FIRE RESISTANCE
}

\section{OF STEEL BUILDINGS}

\author{
T. Jelinek ${ }^{1}$, V. Zania ${ }^{2}$, L. Giuliani ${ }^{2 *}$ \\ ${ }^{1}$ Winning Steel s.r.o., Krizikova 72a, 61200 Brno, Czech Republic \\ ${ }^{2}$ Civil Engineering Department, Technical University of Denmark, 2800 Kgs. Lyngby, DK
}

*Corresponding author: Assoc. Prof. Luisa Giuliani, Section of Building Design, Department of Civil Engineering, Technical University of Denmark, Building 118, Kgs. Lyngby 2800, Denmark Tel.: +45-45251812, e-mail: lugi@byg.dtu.dk 


\section{Abstract}

Current design procedures do not account for the concomitant or subsequent occurrence of earthquakes and fires, which has so far been justified by the low probability of occurrence of accidental actions. Nevertheless, fires are often triggered as a consequence of damage caused by the earthquake and are responsible for casualties and major additional damage to buildings and other constructions. Despite a number of research studies on the topic, it is at present unclear as to what extent the occurrence of a previous earthquake could affect the response of a structure to fire.

The response of a moment-resistant steel frame to post-earthquake fires (PEFs) is investigated and compared with the response of the undamaged frame exposed to fire only, by means of numerical analyses performed using a commercial finite element software. The frame considered as a case study is not insulated against fire, but it is designed to comply with the service damage limitation prescribed in EN1998-1 [1]. The nonlinear seismic response to 7 different earthquakes scaled at the same peak ground acceleration (PGA) is analyzed; while two of these earthquakes are selected for the postearthquake fire (PEF) computations related to the obtained residual inter-story drifts. Thereafter a number of critical fire scenarios are identified, based on the vicinity of the fire to the highest permanent deformation induced by the earthquakes. The structural elements involved in each fire scenario are considered to be exposed to a standard fire and the collapse mode and time are determined by means of large deformation analysis.

The comparison of the mode and time of the frame collapse for all the investigated scenarios shows a minor influence of the effect of the two considered earthquakes on the fire resistance of the frame. The current study shows that nonlinear geometric effects do not have a significant effect in the behavior of the building during fire, when the structure is designed to comply with the service damage states prescribed in EN1998-1 [1].

\section{Keywords}

Multiple hazards; Post-Earthquake Fire; Fire scenarios; Steel structure; Moment-resistant frame. 


\section{INTRODUCTION}

\subsection{Design for accidental actions}

Events such as fires, explosions, or impacts have a very low probability of occurrence within the lifetime of a building structure, but can have very high consequences in terms of both safety of the occupants and loss of the properties. The risk associated with those actions can therefore be high. Hence, most national and international standards $[2,3,4]$ prescribe that the overall stability of the structural system must be ensured also under the occurrence of such low probability - high consequence events.

Due to the low probability of occurrence and the lack of statistical data for a probabilistic characterization of the actions associated with these events, the so called semi-probabilistic approach applied to ordinary design actions such as wind and earthquakes is not followed, but compliance with a special accidental design situation is required by the Eurocodes [5]. In the corresponding load combination, the concomitancy of two accidental actions is disregarded, in consideration of the rarity of such a concomitant occurrence of two low-probability events. While this assumption is sensible for statistically independent actions such as arsons and floods, it is not justified in case of interdependent events such as flood following a hurricane, or fire induced by explosions or by earthquakes [6].

The causes that may trigger a fire during or just after an earthquake are numerous: electrical and gasrelated failures are most common fire triggering events, but also overturning or displacement of heat sources are likely [7]. For this reason, the timing of the earthquake plays a crucial role in the fire spread in buildings (e.g. home heating and electrical or gas appliances are used more in the evening hours and in the winter time), while large scale fire spread is instead significantly affected by the wind conditions. Fires that are directly caused by such earthquake-related failures should be therefore distinguished by other fires, such as e.g. those occurring in buildings that had previously been damaged by an earthquake, before reparations are undertaken $[8,9]$, by using a name such "earthquakeinduced fires". However, the terms Fire Following Earthquake (FFE) or Post-Earthquake Fire (PEF) are commonly used in literature and the latter is also adopted in this paper. 


\subsection{Historical perspective}

In the last century several post-earthquake fires (PEFs) grew into disastrous dimensions [10]. The 7.8 Mw earthquake that struck San Francisco in 1906 and the 7.9 Mw earthquake that hit Tokyo in 1923 were followed by fires that are considered to belong to the most destructive ones during a peaceful time [10]. Other countries that experienced severe PEFs were New Zealand, where a 7.8 Mw earthquake hit Napier in 1931, and Turkey, hit by a $7.8 \mathrm{Mw}$ earthquake in Izmit, in 1999. United States were again struck by PEFs after the 7.1 Mw Loma Prieta earthquake in 1989 and the $6.7 \mathrm{Mw}$ Northridge earthquake in 1994. Japan was also struck by severe PEFs after the 7.9 Mw earthquake that hit Kobe in 1995, as well as after the 9.0 Mw earthquake that struck the east coast in 2011, which also caused a tsunami and the Fukujima nuclear disaster [11].

Even though not all strong quakes are followed by major fires (this is e.g. the case of the 7.1 Mw and 6.2 Mw earthquakes that hit Christchurch, New Zealand, in 2010 and 2011, respectively [12]), postearthquake fires often cause more damage than the quake itself. In the above mentioned cases of the San Francisco and Tokyo earthquake, for example, the PEFs were responsible of ca. $80 \%$ of the total damage.

Since the current seismic design philosophy allows for plastic damage of the load-bearing structure (EN 1998-1, 2004), while the fire design is carried out by assuming undamaged structural elements, a reduced fire resistance of a building subjected to a prior earthquake can be expected. Likely, damage to active fire systems (e.g. water hoses or sprinklers) as well as passive fire measures (such as fire compartmentalization or element insulation) would further reduce the fire resistance. The development of design methodologies and procedures for designing building capable to resist PEFs and their inclusion in codes and guidelines seems therefore an urgent issue.

\subsection{State of the art}

The majority of research on PEFs has been performed during the past two decades. The vast majority of published numerical studies indicate that PEFs can impair the structural integrity of steel buildings. 
However, the fire scenarios and material modeling assumed in the investigations along with the computed impact of a PEF varies amongst the different studies.

Della Corte et al. [13] carried out one of the first comprehensive studies on PEF response of unprotected moment-resisting steel frames. By means of a parametric study of simple frames and a numerical analysis on two multi-story frames, Della Corte et al. [14] showed that the fire resistance is reduced by increasing damage caused by an earthquake on the examined frames.

Other studies have reached a similar conclusion, by employing a push-over analysis to determine the seismic response of unprotected moment-resisting steel frames designed according to Eurocode (EN1998-1, 2004) and by considering both standard and natural curves as fire exposure [15, 16]. Vertically travelling fires in tall steel structures were also investigated by Behnam and Ronagh [17], while Behnam [18] compared the PEF performance of regular and irregular tall steel structures, demonstrating that irregular buildings suffered more damage during earthquakes than regular ones and hence showed a lower fire resistance after the earthquake.

Faggiano and Mazzolani [19] investigated the structural performance of steel frames exposed to PEFs by means of a robustness assessment method, based on the consideration of the seismic performance levels indicated in FEMA 356 [20] and on the evaluation of the consequences of potential subsequent fires. A study on 3-dimensional steel frame performance subjected to post-earthquake fire was conducted by Pantousa and Mistakidis [21]. Their parametric study explored the influence of strains and rotations in plastic hinges induced by earthquake on fire resistance and concluded that the fire resistance of a structure is reduced by earthquake induced permanent deformations.

Only Memari et al. [9] reached different conclusions, by focusing on the effect of a reduced beam section in the beam-column connection of moment-resistant unprotected frame. The analysis was conducted using nonlinear dynamic analysis to determine seismic response and uncoupled thermalmechanical analysis to assess the effects of subsequent parametric fires with cooling phase. The results showed that the global performance of the investigated frames was not affected by an earthquake. However, even though the extension of the fire in the assumed fire scenarios was rather big, 
only symmetric fire configuration was considered, which may not represent the most critical position for the fire.

Even though the majority of research on PEFs focuses on unprotected structures, Yassin et al. [22] highlighted the importance of considering the role of fire protection on steel structure, since it is likely to get damaged during the earthquake and consequently to further reduce the fire resistance of protected structures. The effect of loss of insulation on fire protected steel building has been abundantly investigated in recent past. Tomecek and Milke [23] showed that even a relatively small loss of fire protection on a 2-dimensional steel column leads to significant reduction of the fire resistance. Similarly Ryder et al. [24] reached the same conclusion by investigating a 3-dimensional steel column protected by sprayed material. Only recently, however, the problem of loss of insulation was investigated in relation to PEFs. In particular, Braxtan and Pessiki [25] focused on beam-column joint of a steel moment frame protected by sprayed fire resistive material and subjected to a PEF. The study showed that the earthquake induces damage to the beam fire protection in the areas where plastic hinges form. This leads, in turn, to a temperature increment in both the joint and the column and results in a faster reduction of the steel strength and stiffness at those locations.

\subsection{Objective and method of the study}

This paper focuses on the structural response of a steel frame to PEFs. The aim of the study is to highlight the failure progression caused by the PEF up to the time of collapse and compare the fire resistance and the failure mechanism with the case where the undamaged structure is subjected to a direct fire only (DF). For this purpose numerical analyses are carried out on a case study represented by an uninsulated frame of a steel building designed according to EN1998-1 [1]. Different earthquake time histories have been selected to match as closely as possible the response spectrum of EN1998-1 [1] and the standard fire curve has been used as fire exposure. Different fire scenarios have been considered and the influence of the fire position has been investigated with respect to the different residual drift of the stories. Hereafter the numerical modeling of the structure and the seismic and fire 
actions are described. Subsequently, the results of the seismic and PEF analysis are presented and the comparison of the outcomes for the PEF and DF cases is summarized.

\section{CASE STUDY}

\subsection{Description of the structure}

The structure chosen as case study is shown in Figure 1. The building represents the main frame of a residential steel building already studied in literature [15]. The load-bearing structure consists of an unprotected steel moment-resisting frame. The elements are made of S235 steel and all beam-column joints are assumed rigid. The frame is not insulated against fire, but is designed to withstand gravity and seismic load according to EN 1998-1 (following the concept of strong column-weak beam). In particular, the design peak ground acceleration (PGA) is $0.32 \mathrm{~g}$ and the damping ratio of the structure is assumed equal to $1 \%$ (modeled here as Rayleigh damping). The design vertical loads are:

- dead load of each floor $\mathrm{G}_{\mathrm{k}}=3.5 \mathrm{kN} / \mathrm{m}^{2}$;

- live load on regular floor $\mathrm{Q}_{\mathrm{k}}=2.5 \mathrm{kN} / \mathrm{m}^{2}$;

- live load on roof floor $\mathrm{Q}_{\mathrm{k}, \text { roof }}=1.5 \mathrm{kN} / \mathrm{m}^{2}$.

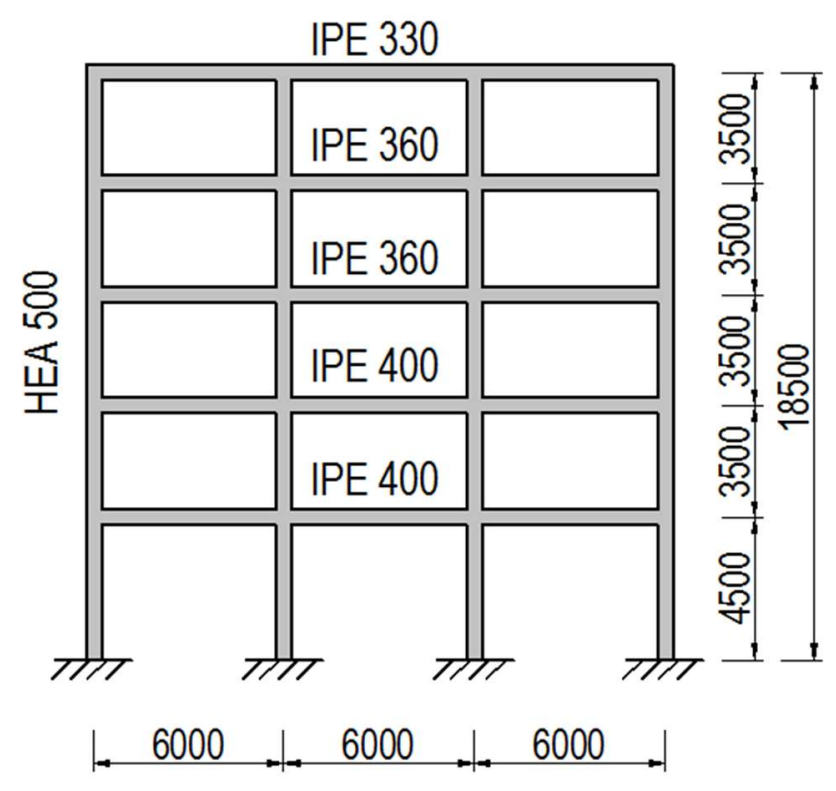

Figure 1: Case study building geometry with dimensions in $\mathrm{mm}$ and section profiles

\subsection{Numerical model}


The structure is modeled in ABAQUS [26] as a 2-dimensional finite element frame [9, 27]. The frame elements are modeled as 2-node Bernoulli beams. The default number of integration points along the section has been increased to 11 , in order to capture the plastic stress distribution with sufficient accuracy. The maximum length of the finite elements used in the model is $1 \mathrm{~m}$, while the finest mesh $(0.25-0.33 \mathrm{~m})$ is used around the joints, in order to accurately simulate the formation of plastic hinges close to the beam-column joints.

An elastic-perfectly plastic material model has been used for the steel at $20^{\circ} \mathrm{C}$. Therefore, no degradation of the mechanical properties due to cyclic loading is considered in the elements. The degradation of both steel stiffness and strength is instead considered as effect of the temperature.

The thermo-plastic stress-strain relation used at different temperatures is shown in Figure 2. In particular, a multi-linear diagram is used, where the yielding curve between the elastic range and the plastic plateau is defined by three points: the first point indicated the end of the elastic branch and is assumed at the $0.2 \%$ proof strength of the steel (i.e. the strength that corresponds to the $0.2 \%$ residual strain after having unloaded the specimen); the third point indicates the beginning of the horizontal plateau and is defined by the ultimate steel strength and a corresponding deformation of $2 \%$; the second point is defined in-between the previous two, with the purpose of giving a proper representation of the yielding curve.

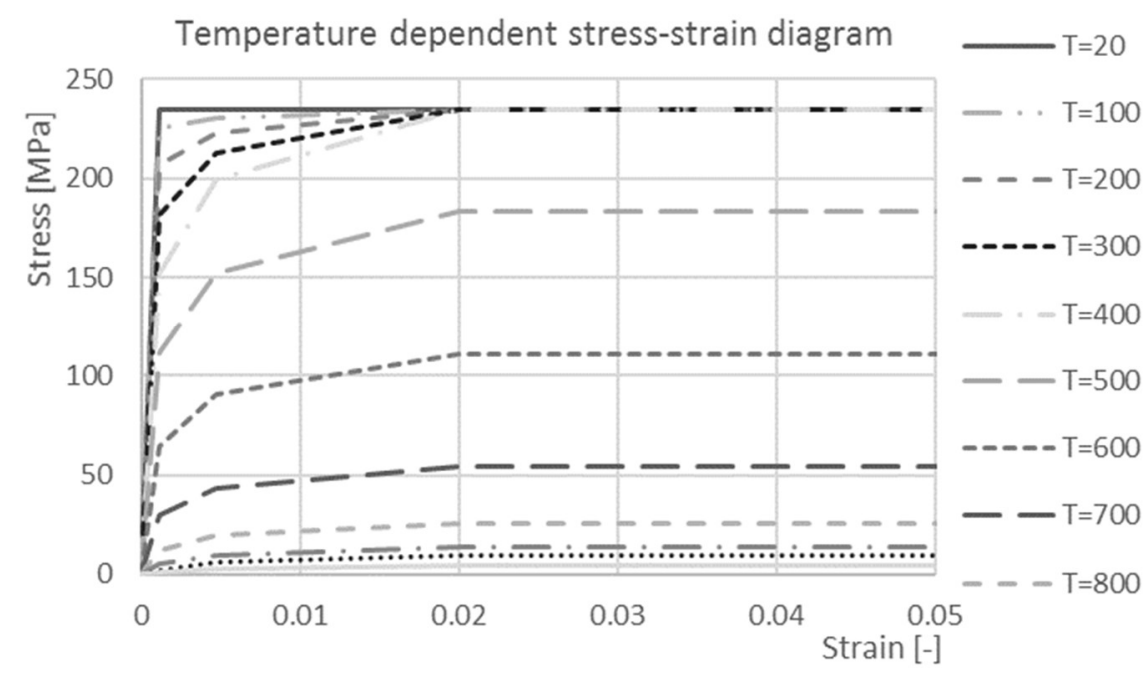

Figure 2: Quadrilinear stress-strain diagram for steel at elevated temperatures 
The degradation of strength and stiffness is modeled according to the Eurocodes. In particular, the proof strength is calculated according to the model defined in Hertz [28] for hot-rolled steel and presented in table E.1 of the Danish National Annex to Eurocode 3 [29], while the degradation of the proportional limit and ultimate strength is calculated according to EN 1993-1-2 [30].

\subsection{Numerical analysis}

The investigation is conducted by means of a sequential analysis, i.e. it consists of the following sequence of separate analysis steps [16]. Geometrical nonlinearities were considered for the last two analysis steps by means of a large displacement formulation.

\section{a. Static load}

The first analysis step is a static linear analysis where the structure is subjected to the gravity load; the load is calculated by using the accidental load combination for earthquake and fire. The Eurocodes indicate the combination factor $\psi_{2}$ in case of earthquake [5] and $\psi_{1}$ in case of fire [31].

However, both coefficients assume the value of 0.3 in case of residential buildings. As such, the resulting design load is the same for both the earthquake and fire combination.

$$
\mathrm{P}_{\mathrm{s}, \mathrm{d}}{ }^{\mathrm{fi}}=\mathrm{G}_{\mathrm{k}}+\psi \mathrm{Q}_{\mathrm{k}}
$$

By considering the values of the dead and live load specified above and by assuming an out-of-plane distance between frames of $6 \mathrm{~m}$, the distributed load on the beams of regular floors is $24.6 \mathrm{kN} / \mathrm{m}$ and on the roof beams is $23.7 \mathrm{kN} / \mathrm{m}$.

\section{b. Earthquake}

The second step is a nonlinear implicit dynamic analysis, where acceleration histories are applied to the base of the structure in order to simulate the earthquake event.

In order to determine structural response to earthquake, 7 acceleration time histories (accelerograms) were chosen from both European and US databases, plus 1 artificial accelerogram (see Table 1 and Figure 3). 
Table 1: List of selected accelerograms

\begin{tabular}{lllll}
\hline No. & Code name & Location & ${\text { Magnitude } \mathrm{M}_{\mathrm{w}}}$ Duration \\
\hline 1 & Artificial & - & - & $30 \mathrm{~s}$ \\
2 & Montenegro E-W & Ulcinij, Montenegro & 6.9 & $40 \mathrm{~s}$ \\
3 & Turkey N-S & Izmit, Turkey & 7.6 & $20 \mathrm{~s}$ \\
4 & Italy E-W & L'Aquila, Italy & 6.2 & $30 \mathrm{~s}$ \\
5 & Hollister & Hollister, USA & 6.9 & $40 \mathrm{~s}$ \\
6 & Northridge & Northridge, USA & 6.7 & $40 \mathrm{~s}$ \\
7 & Loma Prieta & Loma Prieta, USA & 6.9 & $40 \mathrm{~s}$ \\
\hline
\end{tabular}
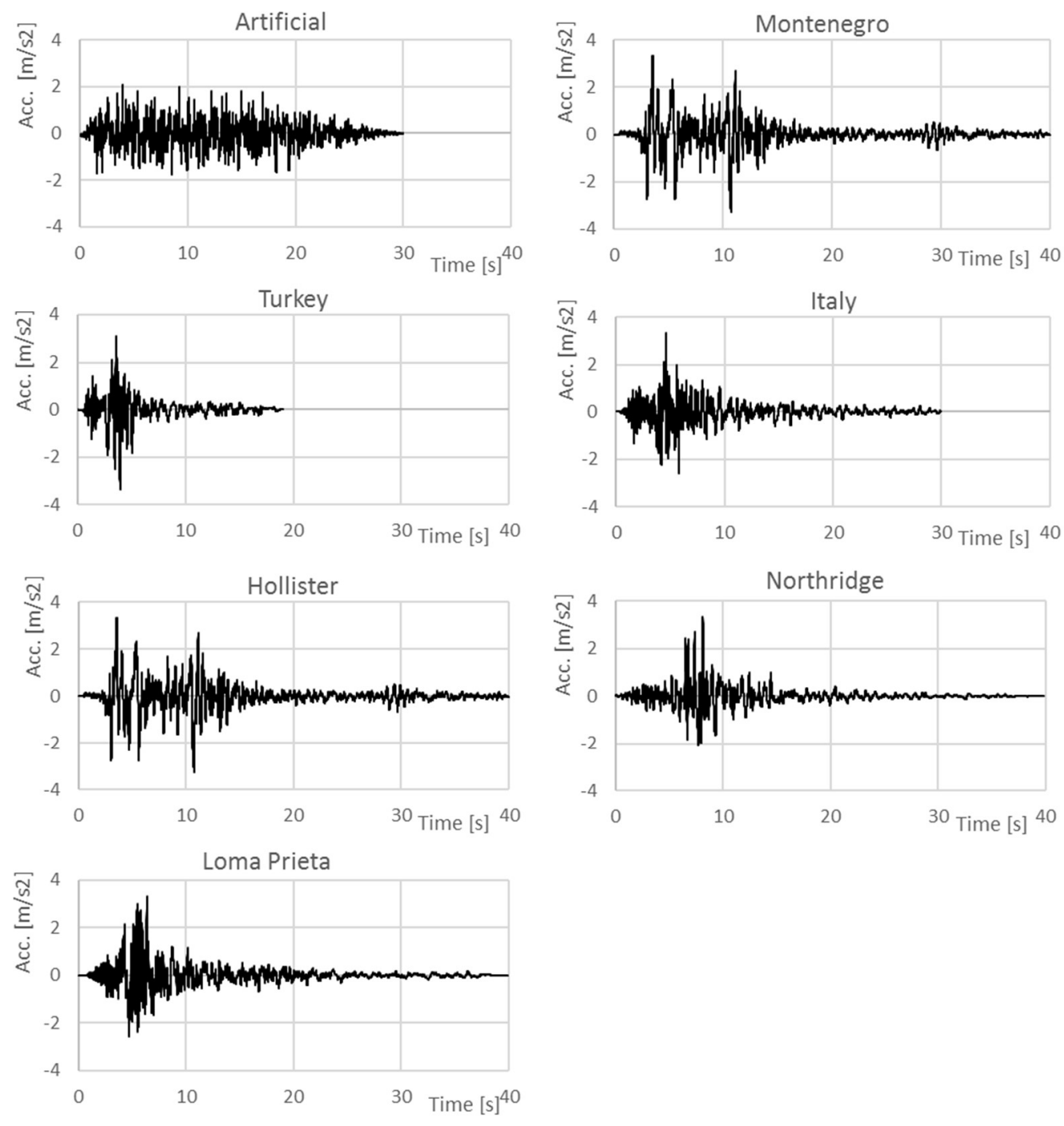

Figure 3: All applied acceleration time histories (accelerograms) in earthquake response analysis. 
All time histories were processed and base line correction and Butterworth type filtering for frequencies between 0.1 and $25 \mathrm{~Hz}$ was applied. Accelerograms were then scaled to PGA $=0.34 \mathrm{~g}$, which is $5 \%$ higher than the design PGA of the steel frame, in order to ensure that plastic deformations develop in the frame.

The earthquake represented by the scaled and corrected accelerogram is applied as imposed motion at the base of the structure. As the ground-floor columns are supposed to be clamped to foundation system, i.e. all degrees of freedom are restricted, the horizontal movement must be allowed so that the seismic motion can be applied. However, in the third step (fire response) the degrees of freedom are restricted again.

In this study the fire is assumed to be triggered just after the dynamic effects of the earthquake on the structure have been dissipated. Since the frame experiences free vibrations right after the earthquake, each acceleration time-history is extended by additional 20 seconds of zero acceleration so that the frame can stabilize and the fire analysis can be performed on a stable structure with residual deformations due to the earthquake. It is noted that the residual vibrations at the end of the additional 20 seconds obtained an amplitude lower than about $10 \%$ of the maximum value; hence it was considered appropriate to disregard them. These vibrations are visible in the beginning of the fire analysis, but vanish after just a few seconds and do not significantly affect the results of the fire analysis.

\section{c. $\quad$ Fire}

The third and last step is also a nonlinear implicit dynamic analysis, where transient effects due to the increasing temperature of exposed structural members are considered, depending on the assumed fire scenario.

The selection of the first fire scenarios is based on the assumption that the fire is contained within one compartment of the building, i.e. below a bay spaced between two subsequent columns. Among the 15 resulting fire compartment scenarios, the most relevant 8 were selected in the bays that experienced the largest drift during the earthquake or where the highest fire damage was expected. These 8 scenarios, plus additional 2 scenarios, where the fire was assumed to spread over the entire floor, 
were then considered in the investigation of the building response to direct fire (DF) and PEF. All investigated scenarios are shown in Figure 4 and identified with a number indicating the floor number (1 to 4 ) and a letter indicating the position of the fire in the frame ( $\mathrm{R}$ for right bay, $\mathrm{C}$ for center bay, $\mathrm{L}$ for left bay, and $\mathrm{F}$ for fire on the whole floor). In each fire scenario, all beams and columns pertinent to the bay or to the floor on fire were considered to be exposed to the fire and therefore subjected to the heating pertinent to each profile section.

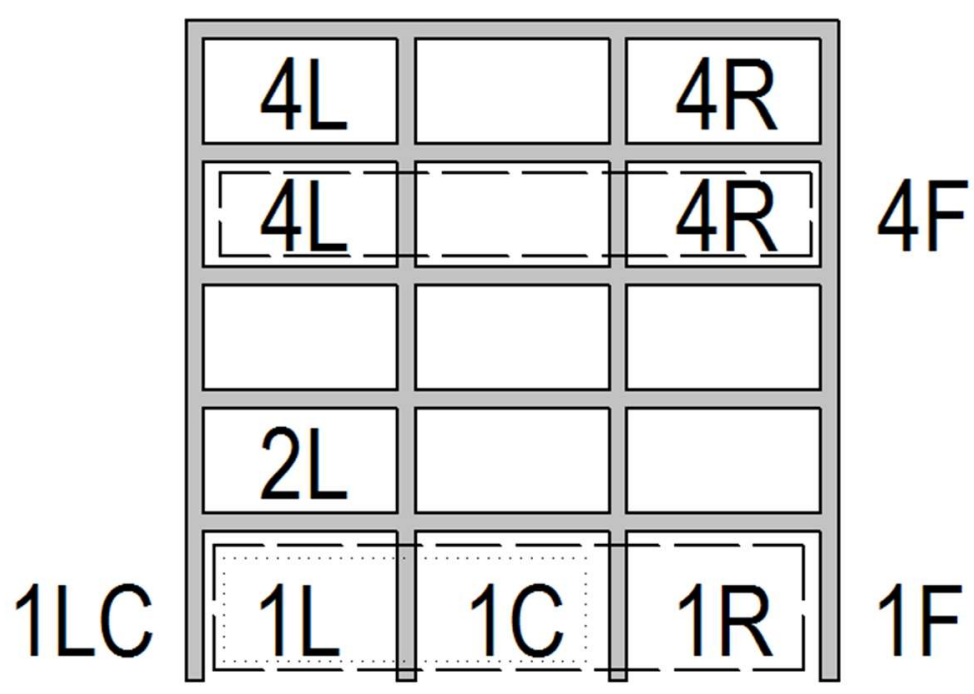

Figure 4: Investigated fire scenarios and abbreviations used in the paper to indicate them

The fire was modeled as standard fire [32]. Although not representative of a real fire, the standard curve has been preferred to parametric or natural fires in order to leave aside the particular ventilation and insulation condition of the compartment and make the resulting fire resistance comparable with the standard resistance classes used for fire element rating.

The heating curve of the exposed steel elements is determined according to what is described in EN 1993-1-2 [30], under the assumption that the temperature distribution is uniform along the profile section. Both outer and inner columns are assumed to be heated from all four sides, while beams are considered exposed on 3 sides only, since the top surface would be protected by the supported slab. The triggering of both local mechanism and global collapse is identified and the time of global collapse is assumed as representative of the frame fire resistance. 


\section{Results}

\subsection{Earthquake response analysis}

A seismic response analysis was carried out for all 7 earthquake events. Then the Artificial and the Montenegro earthquakes were selected for the investigation of the consequent fire response analysis (Figure 5). The Artificial earthquake was chosen due to its relatively good fit to the Eurocode response spectrum (EN 1998-1, 2004) which was used to design the building. In contrast, the spectrum of the Montenegro earthquake is higher than the Eurocode spectrum particularly for the first (swaying) mode $(1 \mathrm{~Hz})$. As a result, larger floor drifts than the ones considered in design are expected, especially at the top floors (see also Table 2).

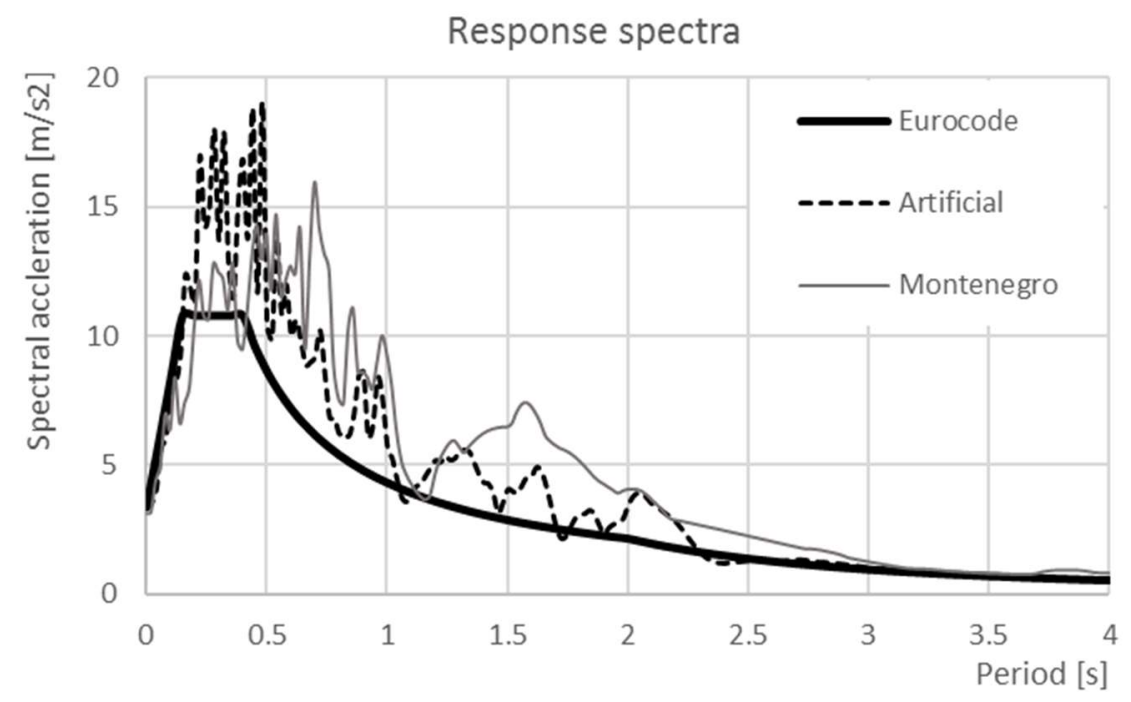

Figure 5: Response spectra of 2 accelerograms and the elastic response spectrum according to EN1998-1 [1].

The results of the seismic analysis are shown in Figure 6 in terms of time history displacement of the roof for the Artificial earthquake (left chart) and the Montenegro earthquake (right chart). In both charts, the time history obtained from the nonlinear analysis is compared with the one obtained from a linear analysis, in order to highlight the time when the energy of earthquake is dissipated by the development of plastic hinges. It is noted that additional 20 seconds of free vibration are added to the accelerograms during the nonlinear analysis, in order to dissipate all dynamic effects before starting the subsequent analysis step. 

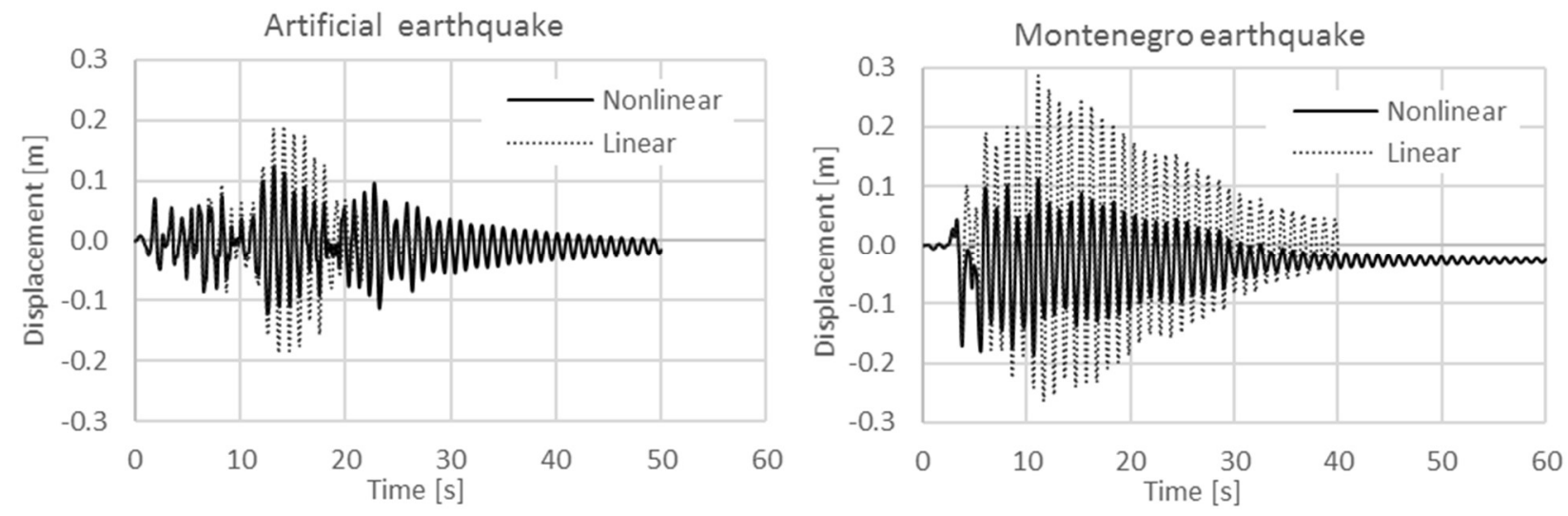

Figure 6: Comparison of displacement response histories of elastic and inelastic systems for Artificial (left) and Montenegro (right) earthquake

Table 2: Maximum displacements and maximum residual strains for all earthquakes

\begin{tabular}{cccc}
\hline No. & Earthquake & Max. displacement & Max. principal strain \\
& denomination & {$[\mathrm{m}]$} & {$[-]$} \\
\hline 1 & Artificial & 0.1237 & 0.0111 \\
2 & Montenegro & 0.1852 & 0.0162 \\
3 & Turkey & 0.1051 & 0.0069 \\
4 & Italy & 0.1047 & 0.0067 \\
5 & Hollister & 0.1056 & 0.0071 \\
6 & Northridge & 0.1069 & 0.0097 \\
7 & Loma Prieta & 0.1517 & 0.0134 \\
\hline
\end{tabular}

In Figure 7, the moment-curvature diagram of a plastic hinge formed during the Artificial earthquake is shown (left end of the beam in $1^{\text {st }}$ level and left bay). The hysteresis loops indicate how much energy dissipates in that particular hinge. The start and the end states are indicated in the chart with two markers (square and triangular, respectively) in order to follow the evolution of the momentcurvature relation. It is worth noting that the section becomes fully plastic at an early stage during the earthquake. However, after several loading and unloading cycles, it ends up to be almost unloaded in its final status. The initial and final moments, even though very close to each other, are not the same, 
presumably due to geometric nonlinearities. The initial and final curvature instead differ significantly from one another, due to the residual plastic deformations.

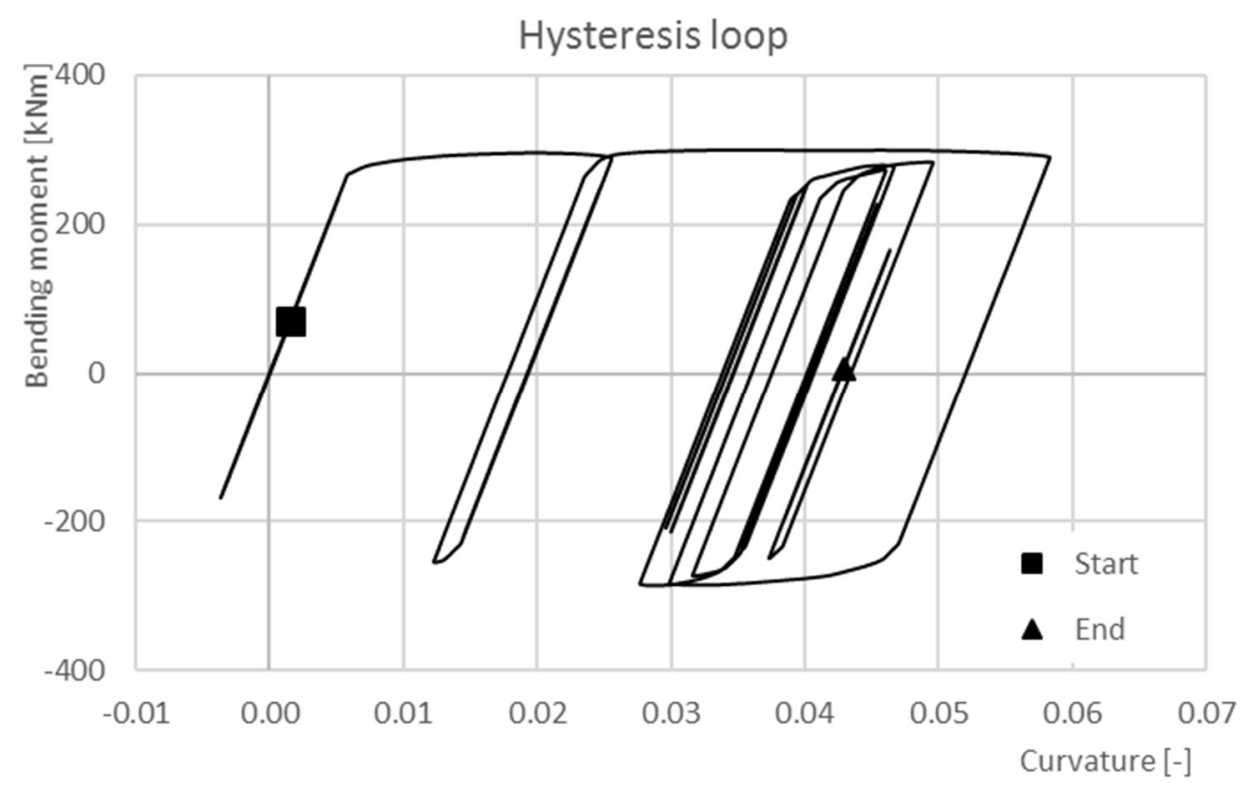

Figure 7: Full hysteresis loops in the joint (left end of the beam at ground floor, left bay)

Figure 8 illustrates the results of the frame deformations in terms of inter-story drift ratios (IDRs) for individual levels. The IDR is defined in the following equation, where $\delta_{i}$ is the displacements at top of the $\mathrm{i}$-th story and $\mathrm{h}_{\mathrm{i}}$ is the story height:

$$
I D R_{i}=\frac{\delta_{i}-\delta_{i-1}}{h_{i}}
$$

The left chart in Figure 8 shows the maximum IDRs for the Artificial earthquake and their envelope (continuous line) along with the residual drift at the end of the seismic motion. It can be observed that the damage limitation prescribed by EN 1998-1 [1] is not exceeded, even though a seismic action meeting the damage limitation requirement would have a larger probability of occurrence than the design seismic action. The right chart shows a comparison of the residual drifts (permanent deformations) caused by each of the 7 earthquakes considered in the analyses. It can be seen that Montenegro and Loma Prieta earthquakes result in the largest IDRs amongst the selected time histories, while the values are still less than half of the required ones [1]. 

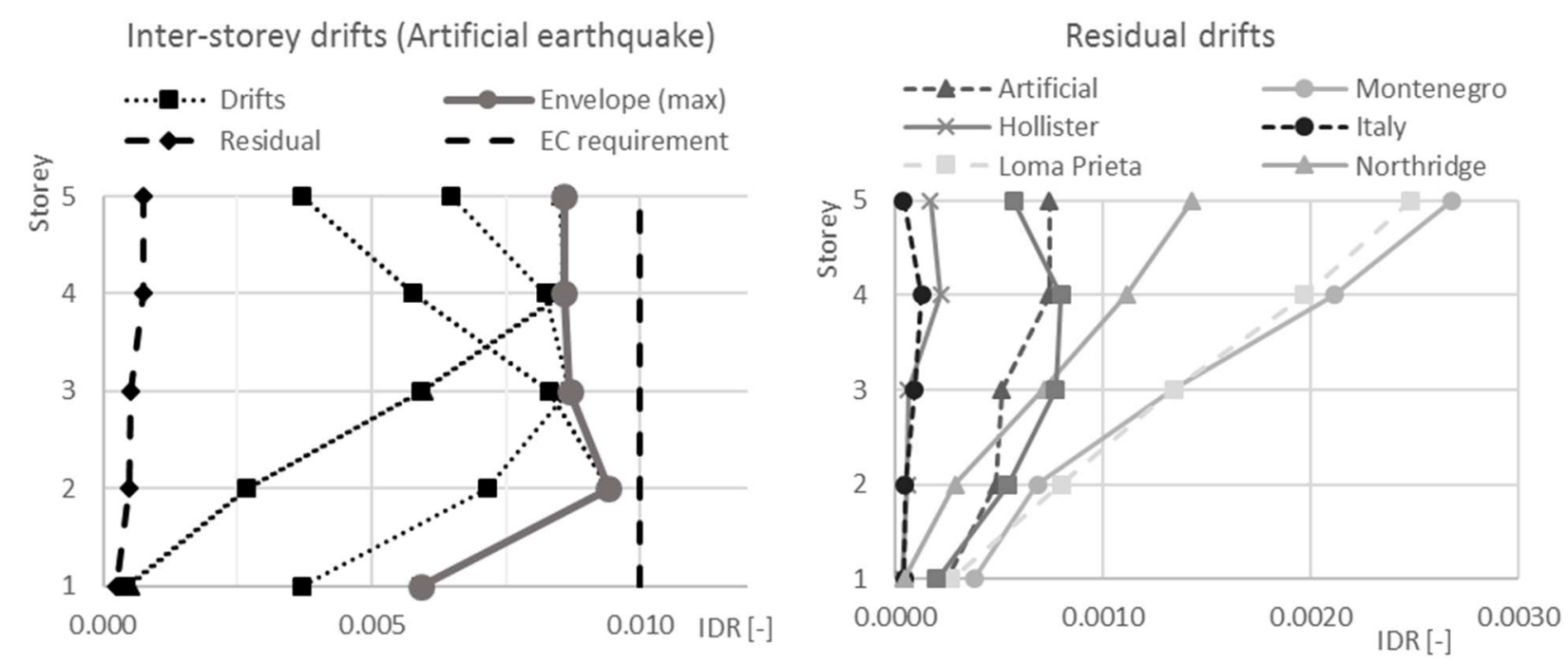

Figure 8: Inter-story drifts for the Artificial earthquake (left) and residual inter-story drifts for all analyzed earthquakes (right).

\subsection{Fire analysis}

The results obtained for each one of the fire scenarios after the Artificial or Montenegro earthquake are summarized in Table 3. For each scenario, the collapse times of the undamaged structure exposed to fire only (reported under the column DF - Direct Fire) can be compared with the collapse times of the PEF analysis (reported in the PEF-A and PEF-M columns for the Artificial and Montenegro earthquake, respectively). The difference between the two collapse times is reported in minutes and as percentage value in the table.

The highest percentage decrement of the fire resistance is observed for the scenario $4 \mathrm{R}$, where the fire has an asymmetric position both along the width (right bay) and the height of the building ( $4^{\text {th }}$ floor), and corresponds to $-3.5 \%$. Such a small reduction level is justified by the rather small residual inter-storey drifts obtained after the earthquake response, as well as the moderate height of the building, which limit the effect of second order moment on the frame column. It is also interesting to note that the type of earthquake does not significantly affect the PEF resistance, as the difference in the collapse time for the Artificial and Montenegro earthquake does not exceed 1/10 of a minute, even though the residual IDLs for the two earthquakes were different. 
Unexpectedly, an increment of the fire resistance corresponding to ca. $6 \%$ is observed for scenario $1 \mathrm{C}$, both in case of the Artificial and Montenegro earthquake. Due to the symmetric and central position of the fire, this scenario was expected to have the lower earthquake and fire damage. An increment in the PEF resistance can indicate that the reduction of resistance due to geometric nonlinear effects on the columns is counterbalanced by an increment of fire resistance caused by a lower moment solicitation of the beam at the end of the earthquake.

In order to better understand the response of the frame to PEFs, the failure analysis of the building is described in detail in the following paragraphs with respect to scenarios A-1L (Artificial earthquake) and M-4L (Montenegro earthquake), as they are representatives of different frame failure modes.

Table 3: Fire resistance of the frame for the various scenarios in case of direct fire (column DF) and fire following the Artifical and Montenegro earthquake (columns PEF-A and PEF-M).

\begin{tabular}{|c|c|c|c|c|c|c|c|}
\hline \multirow{5}{*}{ Scenario } & \multirow{4}{*}{$\begin{array}{l}\text { DF } \\
\text { Collapse } \\
\text { time }\end{array}$} & \multicolumn{6}{|l|}{ PEF } \\
\hline & & \multicolumn{3}{|c|}{ A (Artificial) } & \multicolumn{3}{|c|}{ M (Montenegro) } \\
\hline & & \multirow{3}{*}{$\begin{array}{l}\text { Collapse } \\
\text { time } \\
{[\mathrm{min}]}\end{array}$} & \multicolumn{2}{|c|}{ Difference } & \multirow{3}{*}{$\begin{array}{l}\text { Collapse } \\
\text { time } \\
{[\mathrm{min}]}\end{array}$} & \multicolumn{2}{|c|}{ Difference } \\
\hline & & & & & & & \\
\hline & {$[\mathrm{min}]$} & & {$[\mathrm{min}]$} & {$[\%]$} & & {$[\mathrm{min}]$} & {$[\%]$} \\
\hline $1 \mathrm{~L}$ & 28.0 & 27.8 & -0.2 & -0.8 & 27.7 & -0.3 & -1.1 \\
\hline $1 \mathrm{C}$ & 32.6 & 34.6 & 2.0 & +6.1 & 34.6 & 2.0 & +6.0 \\
\hline $1 \mathrm{LC}$ & 25.5 & 25.5 & 0.0 & -0.1 & 25.5 & -0.1 & -0.3 \\
\hline $1 \mathrm{~F}$ & 23.6 & 23.4 & -0.2 & -0.7 & 23.3 & -0.3 & -1.2 \\
\hline $2 \mathrm{~L}$ & 35.7 & 35.5 & -0.2 & -0.5 & 35.5 & -0.2 & -0.5 \\
\hline $4 \mathrm{~L}$ & 45.8 & 44.8 & -1.0 & -2.2 & 44.8 & -1.1 & -2.3 \\
\hline $4 \mathrm{R}$ & 45.8 & - & - & - & 44.2 & -1.6 & -3.5 \\
\hline $4 \mathrm{~F}$ & 40.7 & 40.4 & -0.4 & -0.9 & 39.9 & -0.8 & -2.0 \\
\hline $5 \mathrm{~L}$ & 20.9 & - & - & - & 20.9 & 0.0 & -0.0 \\
\hline $5 \mathrm{R}$ & 20.9 & - & - & - & 20.9 & 0.0 & -0.0 \\
\hline
\end{tabular}




\section{Scenario 1L (A-1L)}

Figure 9 shows the deformation of the frame at 4 times in the analysis, specifically at 0 min (initial state), $20.1 \mathrm{~min}$ (triggering of catenary effect on the beam) and at $27.8 \mathrm{~min}$ (failure of both columns leading to global collapse immediately after). The failure mode of the frame can be followed by looking at the progression of the element plasticization (colored part of the frame). The failure starts in the beam and then progresses to the outer column, eventually involving the inner column as well. This failure corresponds to the global collapse of the frame, which occurs after ca. 28 min, clearly visible in the bottom right picture of Figure 9.

The behavior of structural elements during the collapse mechanism can be better understood by looking at the section forces of the beam and left column reported in Figure 10 and Figure 11 respectively with respect to the element temperature (upper charts) and time of fire exposure (bottom charts):

- At the beginning of the fire, all heated elements expand in the longitudinal direction. While the expansion of the columns is quite limited, due to the restraint offered by the upper part of the frame, the expansion of the beam (left chart of Figure 10) is more significant and causes the left outer column outwards movement. This, in turn, causes an increment in the bending moment of the left column, as the flexural stiffness of the column opposes to the outer displacement of the beam (right chart of Figure 11).

- As the steel heating progresses, the steel mechanical properties degrade and the load bearing capacity of both beams and columns decrease (indicated with a dotted line in the charts of Figure 10 and Figure 11). Plastic hinges develop first at the beam-ends, inducing higher deflection and moment at the beam mid-span (right chart of Figure 10). Soon after, a third plastic hinge forms at mid-span of the beam, when it becomes a mechanism and loses its ability to carry the load.

- After the formation of the mechanism, the beam deflection increases rapidly, while the axial stresses in the beam begin to decrease (left chart of Figure 10) and the left column is called back inward. This behaviour, caused by the nonlinear effect of the beam elongation, is often responsible for triggering a catenary in the beam, as described in Aiuti et al. [33]. In this case, the value of the 
compressive axial force reverts after ca. $20 \mathrm{~min}$ of fire exposure, but, due to the high beam temperature at this time $\left(\mathrm{ca} .700{ }^{\circ} \mathrm{C}\right)$, only a small catenary develops in the beam.

- The formation of the beam mechanism is closely followed by the failure of the left column first and of the right column shortly after. At this point, the frame remains unsupported for $2 / 3$ of its width, which causes the structure to bend down, presumably leading to the failure of the two cold columns and resulting in a global collapse of the whole frame.

It should be noted that before the first column fails, the increasing rotation at the beam-ends reaches the ultimate value (around $25 \mathrm{~min}$ ). Consequently, the following failure progression is rigorously valid only in case the beam is not detached by the frame. However, since the temperature in the beam is quite high when the ultimate strain is reached, the redistribution of stress on the adjacent elements would be minimal and therefore would not affect the collapse significantly.

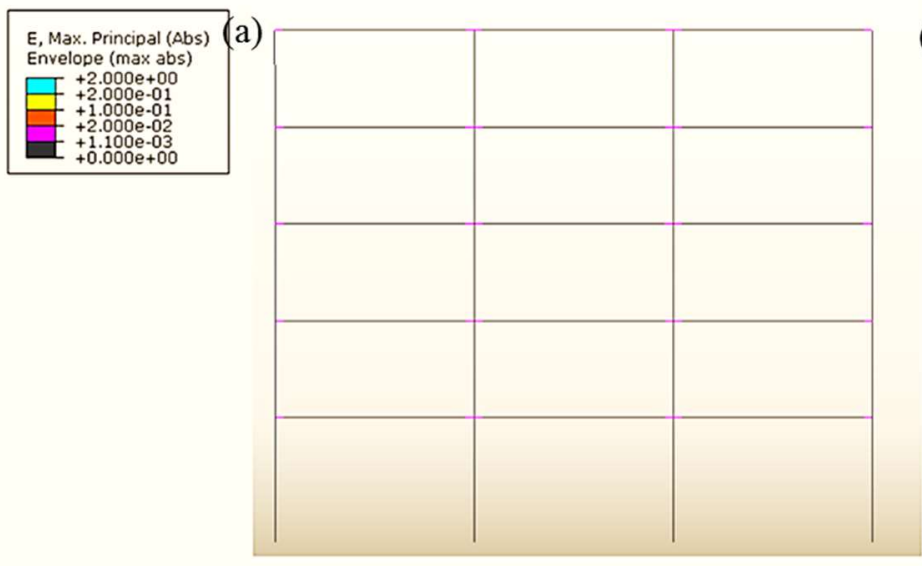

(c)

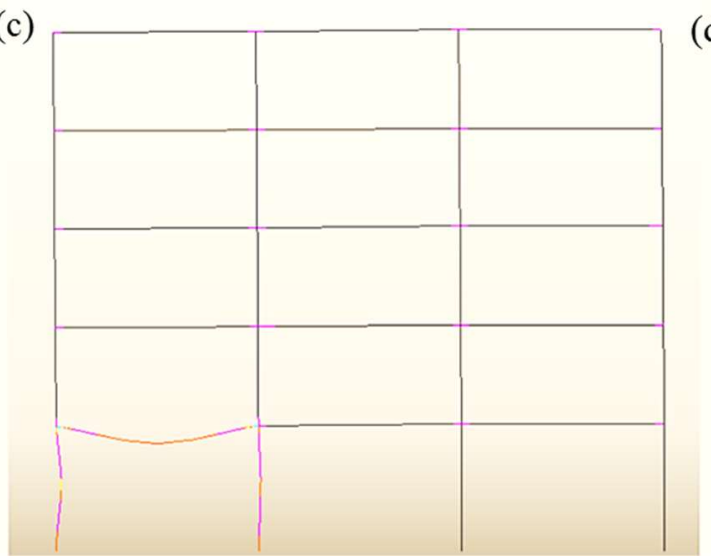

(b)

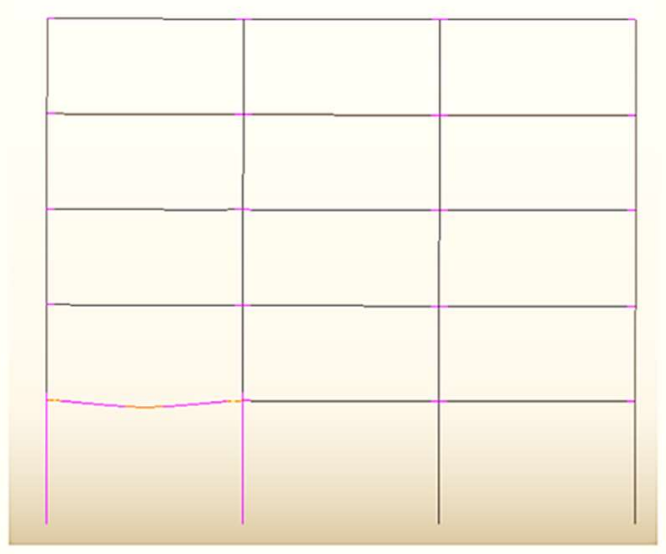

(d)

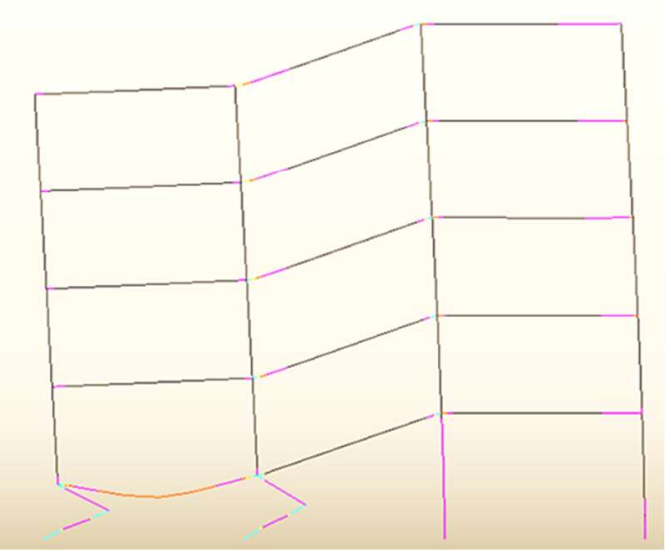

Figure 9: Global collapse mechanism (Scenario A-1L): initial state at 0 min (a), catenary effect at $20.1 \mathrm{~min}$ (b), failure of columns at $27.8 \mathrm{~min}$ (c) and global collapse 2 seconds later (d). 

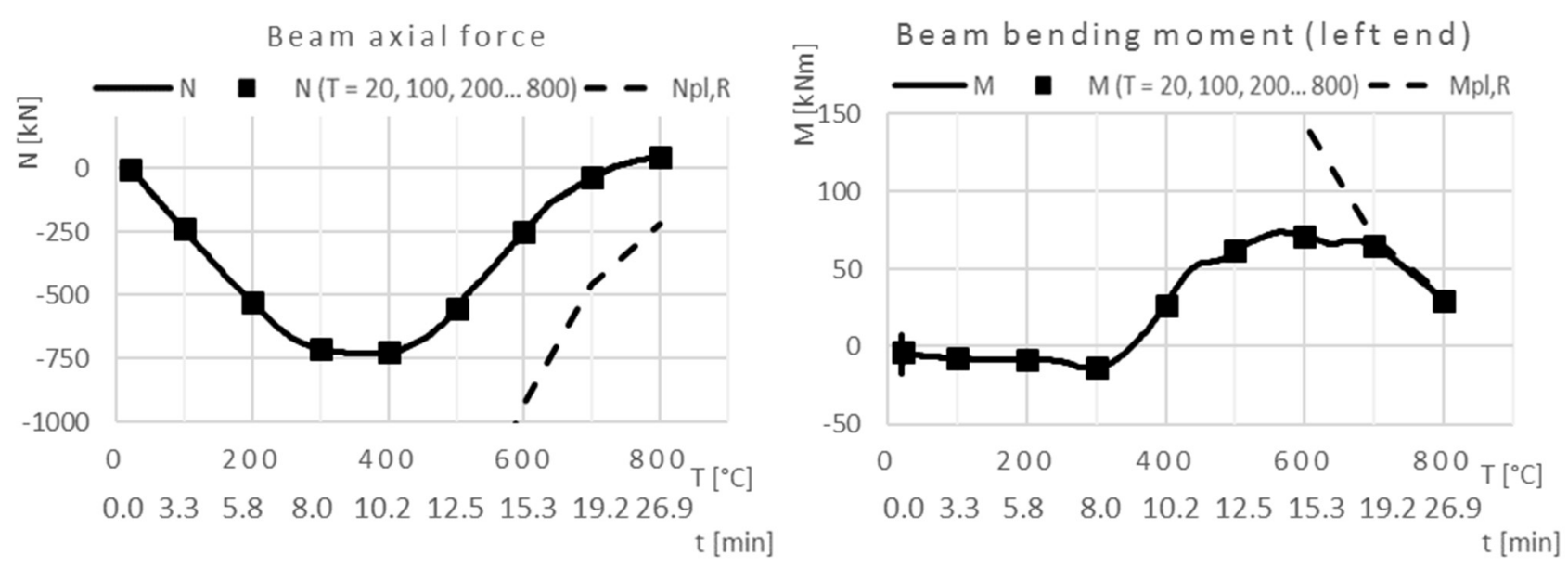

Figure 10: Axial force in the beam (left charts) and moment at the beam left end (right charts) in the A-1L scenario, plotted against the beam temperature (upper axis) and the time of fire exposure (bottom axis). The dotted lines in the left and right charts represent the axial and bending resistance, respectively.
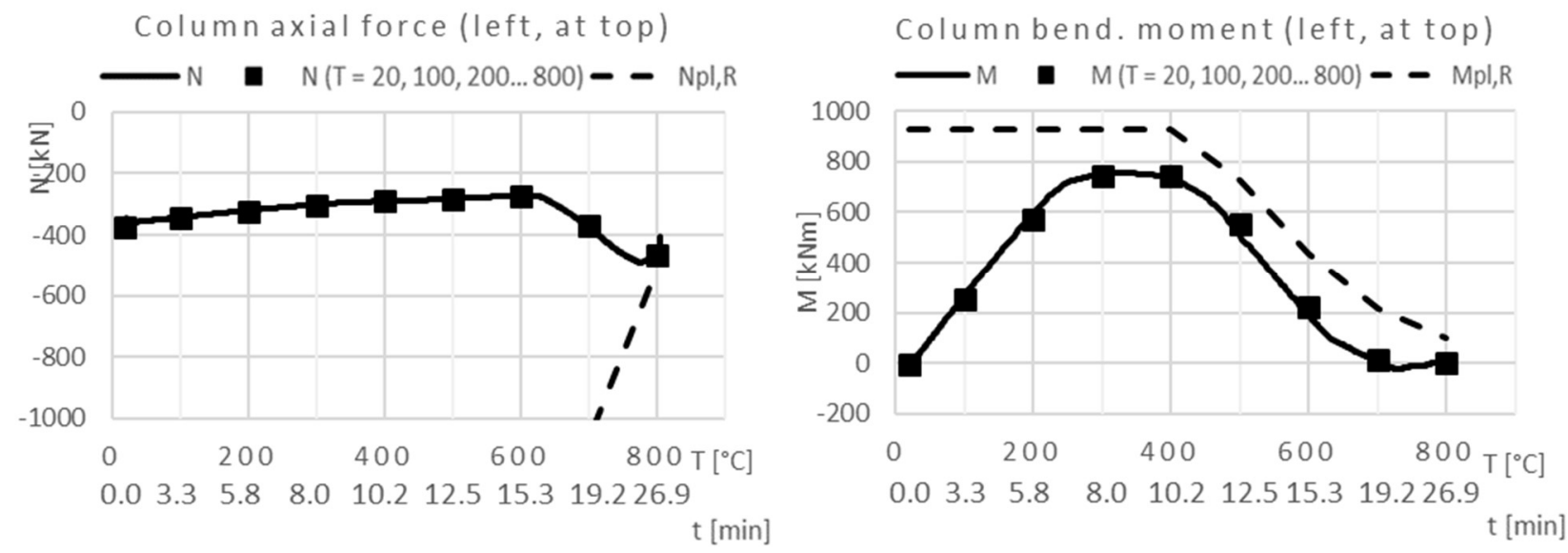

Figure 11: Axial force in the column (left chars) and moment at the top of the left column (right chart) in the A-1L scenario, plotted against the beam temperature (upper axis) and the time of fire exposure (bottom axiss). The dotted lines in the left and right charts represent the axial and bending resistance, respectively.

Both the time of global collapse and the failure progression induced by the post-earthquake fire (PEF) is almost identical to what obtained by investigating the response of the undamaged frame to direct fire (DF), i.e. without the consideration of a prior earthquake. In particular, in the PEF case, the beam failure occurs ca. $10 \mathrm{~s}$ earlier than it would in case of DF. This is visible in Figure 13, where the moment distribution on the heated beam are reported for both PEF and DF analyses and the different sectional failures are highlighted. It can be seen that, despite the different initial value of the moment, 
the development of the moment becomes almost the same after ca. $500 \mathrm{~s}$ of analysis, when the compressive force in the beam starts to decrease. The negligible time difference in the beam failure reflects on the time of global collapse of the frame, which is delayed by ca. 13 seconds in the PEF case.

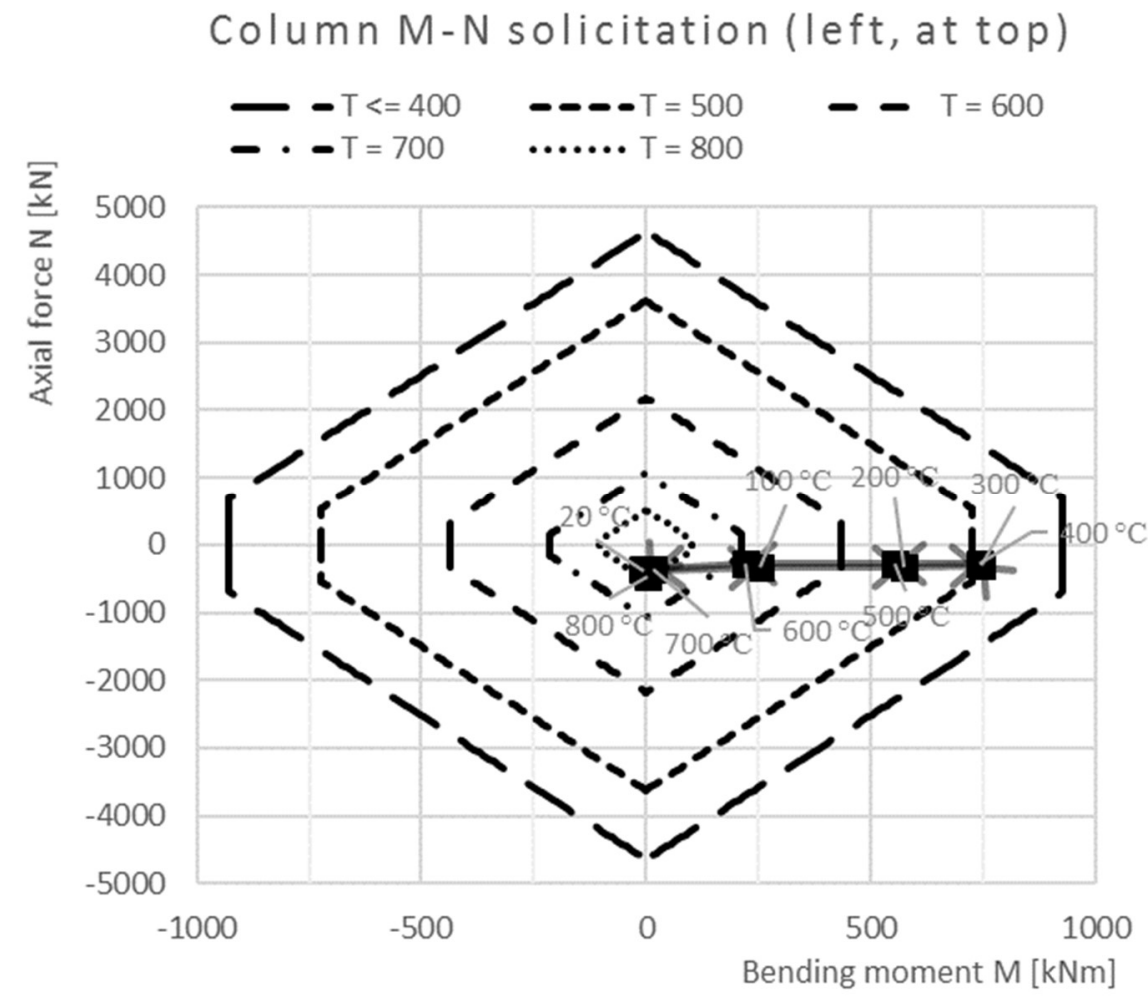

Figure 12: Interaction diagram of axial force and bending moment at top of the left column with resistance envelope shrinking with elevated temperature

Comparison of bending moment histories (left end of beam)

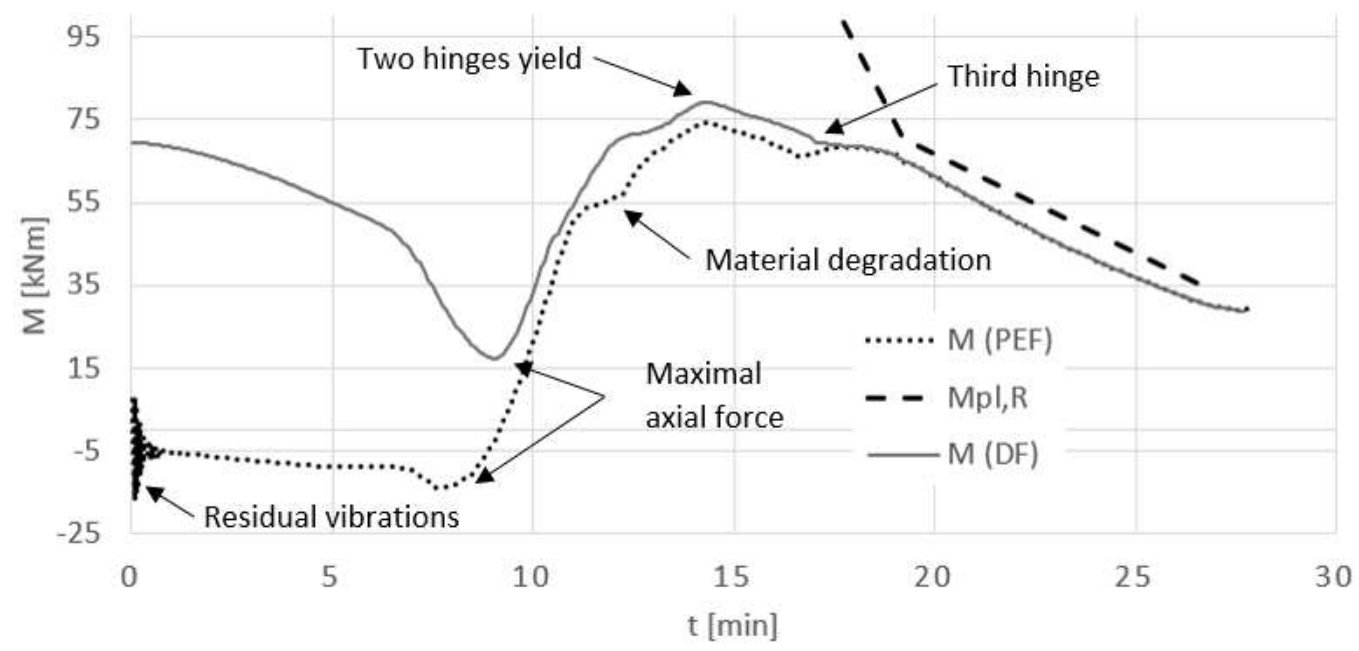

Figure 13: Comparison of bending moment histories in case of DF and PEF for A-1L scenario (left end of the heated beam) 


\section{Scenario 4L (M-4L)}

If the fire is assumed to develop in the left bay at the fourth floor $(4 \mathrm{~L})$, the frame collapse is significantly delayed with respect to the previous $1 \mathrm{~L}$ scenario and occurs around $45 \mathrm{~min}$ of fire exposure. This is due to the fact that, since the same steel profile is used for all columns, the utilization factor of the top columns, which carry less load, is much lower than for the bottom columns. The frame experiences a different failure mode, which leads to a partial collapse of the upper part of the frame. Also in this scenario, the DF analysis shows no significant difference in the failure mode and in the time of global collapse, which happens 1 minute later than in the PEF case.
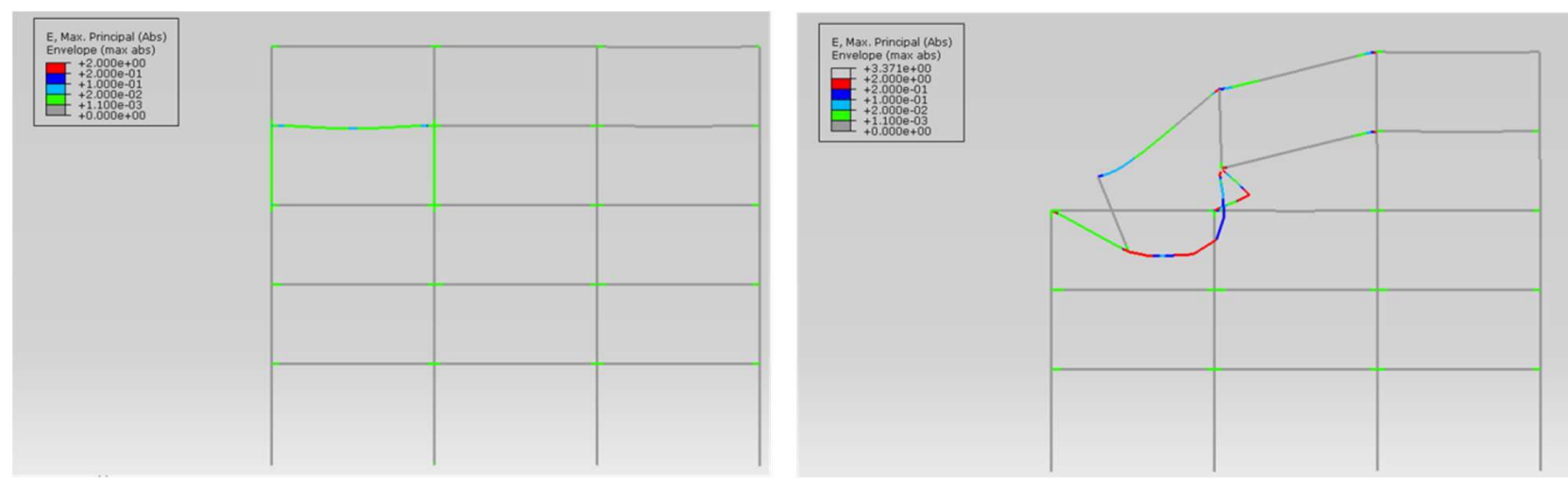

Figure 14: Collapse of the frame for M-4L scenario (formation of three hinges at 14.9min - left, partial collapse at $44.8 \mathrm{~min}$ - right)

\section{CONCLUSIONS}

A PEF investigation of an uninsulated moment-resisting steel frame was presented. Two different earthquakes were considered and a number of fire scenarios were analysed. In all cases, the difference in the obtained fire resistance of the frame, expressed as time of global collapse, was minor.

This is explained by the fact that, being the frame designed in compliance with the damage limitation (SLS) prescribed in EN1998-1 [1], the permanent deformations induced in the frame by earthquakes close to the design earthquake magnitude were relatively small. In particular, the maximum residual principal strains reached in the plastic hinges were in the range of $0.6-1.6 \%$, while the maximum displacements of the roof were between 10 and $19 \mathrm{~cm}$. The inter-story drifts fulfill the damage limitation indicated in EN 1998-1 in case the applied earthquake fits at least roughly the elastic response 
spectrum (EN1998-1, 2004). Since the permanent deformations after the earthquake are small, the geometrical effects that influence the fire response after the earthquakes are insignificant and neither the progression of the failures nor the time of collapse are considerably affected.

It is here recalled that an elastic-perfectly plastic material model was considered in the seismic analyses. Therefore, the additional effect of plastic damage to the fire resistance was disregarded in the analysis and the variation of the fire resistance is therefore only ascribable to the geometrical effects due to the different initial geometry at the beginning of the fire in the PEF and DF case. Further assumptions that may affect the global time of collapse are related to the $2 \mathrm{D}$ modeling of the frame, which does not allow consideration of possible out-of-plane failure of the columns (as the out-ofplane deflection of the beams would be hindered by the floor slab). However, this limitation affects in the same way the PEF and DF analyses. Hence, it should not affect the conclusion concerning the limited influence of a prior earthquake on the global collapse of the frame.

This conclusion could instead change significantly in case an insulated steel structure would be considered, as the fire resistance would then be greatly reduced by the damage likely caused by the earthquake to the fire protection material. Furthermore, different conclusions on the influence of PEF are also possible to occur in case the PGA for the earthquake response is increased.

\section{REFERENCES}

[1] EN 1998-1, "Eurocode 8: Design of structures for earthquake resistance - Part 1: General rules, seismic actions and rules for buildings," European Committee for Normalization, Brussels, Belgium, 2004.

[2] SEI/ASCE 7-02, "Minimum Design Loads in Buildings and Other Structures," American Society of Civil Engineering (ASCE), Structural Engineering Institute (SEI), Reston, Virginia, US, 2002.

[3] ISO 2394, "General principles on reliability for structures," International Organization for Standardization (ISO), 2015. 
[4] EN1991-1-7, "Eurocode 1: Actions on structures - Part 1-7: General actions -Accidental actions," Comité Europeen de Normalization (CEN), Brussels, Belgium, 2006.

[5] EN1990, "Eurocode 0 - Basis of structural design," Comité Européen de Normalisation, Brussels, Belgium, 2002.

[6] G. Lee, Z. Liang, J. Shen and J. O’Connor, "Extreme Load Combinations: A Survey of State Bridge Engineers,” Technical Report MCEER-11-0007, Buffalo, New York, US, 2011.

[7] F. Rahmanian and I. Ismail, "Fire After Earthquake," University of Canterbury, Canterbury, New Zealand, 1992.

[8] S. Mousavi, A. Bagchi and V. K. R. Kodur, "Review of post-earthquake fire hazard to building structures," Canadian Journal of Civil Engineering, vol. 35, pp. 689-698, 2008.

[9] M. Memari, H. Mahmoud and B. Ellingwood, "Post-earthquake fire performance of moment resisting frames with reduced beam section connections," Journal of Constructional Steel Research, vol. 103, pp. 215-229, 2014.

[10] C. Scawthorn, J. M. Eidinger and A. Schiff, Fire following earthquake, vol. 26, US: ASCE Technical Council on Lifeline Earthquake Engineering, Monograph No.26, 2005.

[11] T. Tanaka, "Characteristics and problems of fires following the Great East Japan earthquake in March 2011," Fire safety journal, vol. 54, pp. 197-202, 2012.

[12] G. B. Baker, P. C. R. Collier, A. K. Abu and B. Houston, "Post-earthquake structural design for fire-a New Zealand perspective,” 2012.

[13] R. L. F. M. M. G. Della Corte, "Post-earthquake fire resistance of moment resisting steel frames," Fire Safety Journal, vol. 38, pp. 593-612, 2003.

[14] G. Della Corte, R. Landolfo and F. Mazzolani, "Post-earthquake fire resistnace of moment resisting steel frames," Fire Safety Journal, vol. 38, pp. 593-612, 2003.

[15] R. Zaharia and D. Pintea, "Fire after earthquake analysis of steel moment resisting frames," International Journal of Steel Structures, vol. 9, pp. 275-284, 2009. 
[16] B. Behnam and H. R. Ronagh, "Post-Earthquake Fire performance-based behavior of unprotected moment resisting 2D steel frames," KSCE Journal of Civil Engineering, vol. 19, pp. 274-284, 2015.

[17] B. Behnam and H. R. Ronagh, "Behavior of moment-resisting tall steel structures exposed to a vertically traveling post-earthquake fire," The Structural Design of Tall and Special Buildings, vol. 23, pp. 1083-1096, 2014.

[18] B. Behnam, "Structural response of vertically irregular tall moment-resisting steel frames under pre-and post-earthquake fire," The Structural Design of Tall and Special Buildings, 2015.

[19] B. Faggiano and F. M. Mazzolani, "Fire after earthquake robustness evaluation and design: Application to steel structures," Steel Construction, vol. 4, pp. 183-187, 2011.

[20] FEMA 356, "Prestandard and Commentary for the Seismic Rehabilitation of Buildings," Federal Emergency Management Agency (FEMA), Washington D.C., U.S., 2000.

[21] D. Pantousa and E. Mistakidis, "Fire-after-earthquake resistance of steel structures using rotational capacity limits," Earthquakes and Structures, vol. 10, pp. 867-891, 2016.

[22] H. Yassin, F. Iqbal, A. Bagchi and V. Kodur, "Assessment of post-earthquake fire performance of steel-frame buildings," in Proceedings of the 14th World Conference on Earthquake Engineering Beijing, 2008.

[23] D. V. Tomecek and J. A. Milke, "A study of the effect of partial loss of protection on the fire resistance of steel columns," Fire Technology, vol. 29, pp. 3-21, 1993.

[24] N. L. Ryder, S. D. Wolin and J. A. Milke, "An investigation of the reduction in fire resistance of steel columns caused by loss of spray-applied fire protection," Journal of fire protection engineering, vol. 12, pp. 31-44, 2002.

[25] N. L. Braxtan and S. P. Pessiki, "Postearthquake fire performance of sprayed fire-resistive material on steel moment frames," Journal of Structural Engineering, vol. 137, pp. 946-953, 2011.

[26] ABAQUS , “User Documentation, Version 6.14,” Dassault Systemes, 2014. 
[27] S. E. Quiel and M. E. M. Garlock, "Modeling high-rise steel framed buildings under fire," ASCE Struct Congr, pp. 1-10, 2008.

[28] K. Hertz, "Reinforcement Data for Fire Safety Design," Magazine of Concrete Research, vol. 56, no. 8, pp. 453-459, 2004.

[29] DS/EN1993-1-2 DK NA, "Danish National Annex to Eurocode 3: Steel Structures, Part 1-2: General rules - Structural fire design," European Committee for Standardization (CEN) , Brussels, Belgium, 2007.

[30] EN 1993-1-2, "Eurocode 3: Design of Steel Structures, Part 1-2: General Rules - Structural fire design,” European Committee for Normalization, Brussels, Belgium, 2005.

[31] DS/EN 1991-1-2 DK NA, "Danish National Annex to Eurocode 1: Part 1-2 Actions on structures exposed to fire," Erhvevs- og Byggestyrelsen, Denmark, 2011.

[32] ISO 834-1, Fire Resistance Tests - Elements of Buildings Construction - Part-1: General Requirement, Switzerland, n: International Organization for Standardization, 1999.

[33] R. Aiuti, L. Giuliani and F. Bontempi, "Fire-induced collapse mechanisms in steel buildings," Turin, Italy, 2013. 